\author{
Military Technical College \\ Kobry El-Kobbah, \\ Cairo, Egypt
}

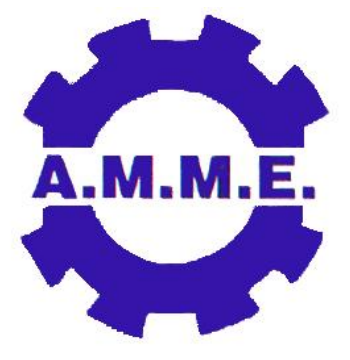

$14^{\text {th }}$ International Conference on Applied Mechanics and Mechanical Engineering.

\title{
Research on Series Hydraulic Hybrid Drivetrain for Using in Automobile
}

By

\author{
Ibrahim-Sokar
}

\author{
H. Murrenhoff **
}

\section{Abstract:}

Nowadays, the demand for energy savings and reduction of greenhouse gases as well as unhealthy emissions of automobile has been highly increased. Also as a result of the yearly rising of fuel prices and new environmental regulations of vehicle emissions; the development of new hybrid vehicles to reduce fuel consumption and emissions is a prerequisite. Hybrid vehicles have three different system configurations; series, parallel and series-parallel. These configurations can be divided into electric hybrid and hydraulic hybrid. Hydraulic hybrids operate basically the same way as electric hybrids, but they use a motor-pump unit instead of an electric motor-generator and a hydraulic accumulator rather than the battery pack to store recuperated energy. The electric hybrid has been promoted and successfully applied in various automobiles by industry. The high power density of hydraulic pumps/motors and hydro-pneumatic accumulators make hydraulic technology look promising for passenger cars and need be integrated in the vehicle industry due to its low price and recently developed units of high efficiency compared to electric machines. Aim of this paper is to introduce the development of using a Secondary controlled/ pressure coupling Hydrostatic Transmission (SC-HST) drivetrain to the new configuration of series hydraulic hybrid drivetrain which is called the Hydrid for use in passenger cars. A key component in the Hydrid drivetrain is the Innas hydraulic transformer and the new technology of using floating cup principle in axial piston hydrostatic pumps, motors and transformers which reveal a higher efficiency up to $98 \%$ [1]. Moreover one of the big merits of using the Hydrid drivetrain is its ability to force the engine to run only under high loads at all vehicle velocities.

\section{Keywords:}


Hybrid vehicle, hydraulic hybrid, Energy Saving and automotive control

* PhD student, Institute for Fluid Power Drives and Controls (IFAS), RWTH-Aachen University, Germany

** Univ.-Prof. Dr.-Ing., Institute for Fluid Power Drives and Controls (IFAS), RWTHAachen University, Germany

A simulation study for the well known secondary control hydrostatic transmission drivetrain and the new and distinct Hydrid drivetrain will be introduced. The work bench vehicle used in this study is mid-size as like a VW-Passat. The effectiveness of the energy saving of the Hydrid drivetrain compared to the traditional secondary control clearly was proven by a simulation model which is built in DSH plus software. In addition, a control strategy, which is used to control the Hydrid drivetrain to follow commands given by a driver is also proposed as on-off control. The simulation results indicate that percentage decrease of the fuel consumption by the Hydrid drivetrain is about $53 \%$ in NEDC cycle compared to a baseline VW-Passat.

\section{Introduction:}

Due to environmental pollution and yearly reduction of fossil fuels used in vehicles, the demand for fuel efficient vehicles has grown. Fuel consumption and consequently $\mathrm{CO}_{2}$ emissions can be reduced considerably by hybridization. This implies adding a secondary power source like an accumulator/battery to the primary power source i.e. the Internal combustion Engine (ICE). A control strategy is necessary to control the power flow from the primary and secondary power source to the vehicle wheels. Figure $1-\mathrm{a}, \mathrm{b}$ shows the basic configurations of series and parallel hydraulic hybrids. As stated, in hybrid electric Vehicles, the system take the same configuration shown where hydraulic pump/motor will be replaced by electric generator/motor and a battery instead of the hydro-pneumatic accumulator. The scope of this study is on series hydraulic hybrid.

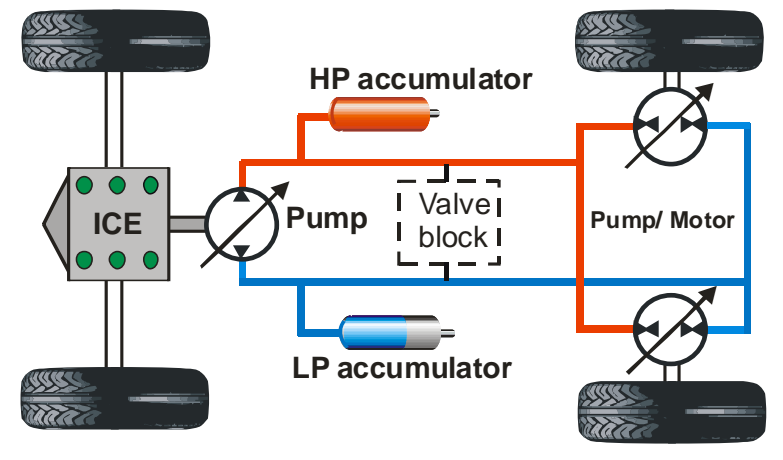

Figure (1-a): Basic series hybrid hydraulic vehicles configuration.

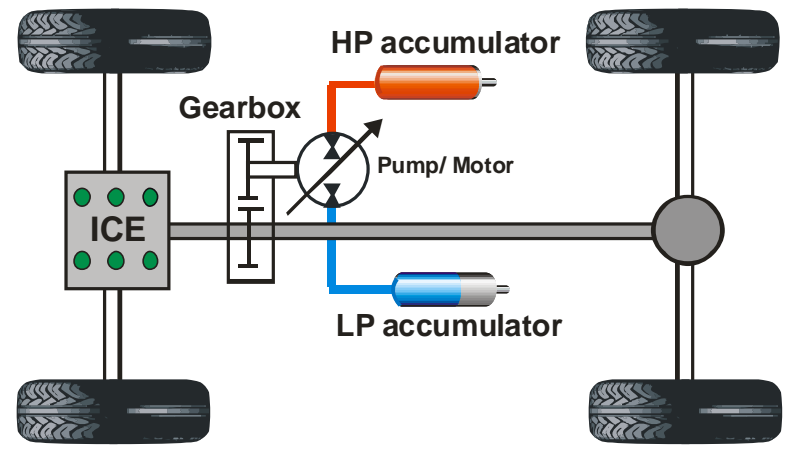

Figure (1-b): Basic parallel hybrid hydraulic vehicles configuration.

A hydraulic hybrid is characterized by its ability to capture regenerative braking energy quickly compared to electric batteries which absorb about $30 \%$ of the braking energy. 
Generally the aim of using hybrid drivetrain is to increase the whole system efficiency by efficient use of the primary power source, efficient transformation of energy for motion and efficient recovering and reuse of braking energy [2].

The mid-sized VW Passat will be used in this study as baseline vehicle to validate the common parameters in simulation models such as the vehicle dynamic model. The vehicle geometrical parameters and engine characteristics are indicated in Table 1. New European Driving Cycle (NEDC) will be used in the simulations to define the driver requirements and it is also considered as an assessment criterion to evaluate the drivetrain variables; the fuel economy and $\mathrm{CO}_{2}$ emissions. Two simulation models of the SC-HST and the Hydrid drivetrains were built in DSHplus 3.6.1 software using the components loss data to study the benefits of implementing hydraulic hybrid in the baseline vehicle.

Table (1): Baseline Vehicle and engine parameters

\begin{tabular}{|l|l|l|l|}
\hline Parameter & Symbol & Value & Unit \\
\hline Curb mass & $m_{F}$ & 1554 & $\mathrm{~kg}$ \\
\hline Frontal area & $A_{f}$ & 2,26 & $\mathrm{~m}^{2}$ \\
\hline Air drag coefficient & $C_{d}$ & 0.28 & - \\
\hline Rolling resistance coefficient (firm Asphalt) & $f_{r}$ & 0.008 & - \\
\hline Wheel radius (4WD) & $r_{W}$ & 0.315 & $\mathrm{~m}$ \\
\hline Maximum vehicle velocity & $V_{F, \max }$ & 220 & $\mathrm{Km} / \mathrm{h}$ \\
\hline Maximum Engine power @ 4200 rpm & $P_{E}$ & 120 & $\mathrm{~kW}$ \\
\hline Maximum engine speed & $n_{E, \max }$ & 4400 & $\mathrm{rpm}$ \\
\hline Maximum Engine Torque @ 1750- 2500 rpm & $T_{E, \max }$ & 370 & $\mathrm{~N} . \mathrm{m}$ \\
\hline
\end{tabular}

\section{Series hydraulic hybrid vehicles:}

In the following introduced series hydraulic hybrids, there are two power sources providing traction power for the in-wheel hydro-motors. The primary power source is an efficient diesel engine while the second is a bidirectional hydro-pneumatic accumulator characterized by its high power-to-energy ratio. The accumulator is pre-charged with $\mathrm{N}_{2}$ at 180 bar. The mechanical transmission is completely omitted and replaced by hydrostatic transmission. A hydraulic pump is coupled to the engine output shaft, while hydraulic motors are connected directly to the vehicle wheel to minimize the mechanical losses. A $20 \mathrm{~L}$ accumulator is located in the high pressure side of both transmission circuits to recuperate the braking energy and restore it to the system when needed. The system secure pressure is adjusted to 420 bar by a relief valve.

The accumulator State Of Charge (SOC) is controlled via a pressure-controller which actuates the engine when the accumulator pressure goes below a specified threshold minimum value i.e. 200 bar. The engine is turned-off when the accumulator pressure goes higher than 400 bar. Therefore the accumulator plays an important role in the system operation dominating the overall performance of the system. Since, a serieshybrid omits a mechanical link between the combustion engine and the wheels; the engine is run at a constant and efficient rate even as the vehicle changes speed. 


\section{1: Secondary controlled Hydrostatic transmission (SC-HST)}

This secondary control name originates from controlling the secondary side of the transmission which is in this case a variable displacement motor. It is considered as conventional series hydraulic drivetrain. It comprises of the following main components as shown in Figure 2, fixed displacement axial piston pump type A4VG, size $71 \mathrm{cc} / \mathrm{rev}$ (Bosch Rexroth), high and low pressure accumulators and variable displacement bidirection hydro-motors type A6VM (Bosch Rexroth), each of size $80 \mathrm{cc} / \mathrm{rev}$ attached directly to the four wheels of the vehicle to reduce mechanical losses. The diesel engine drives a fixed displacement pump, which draws fluid from a low pressure reservoir and pressurizes it to a high pressure accumulator.
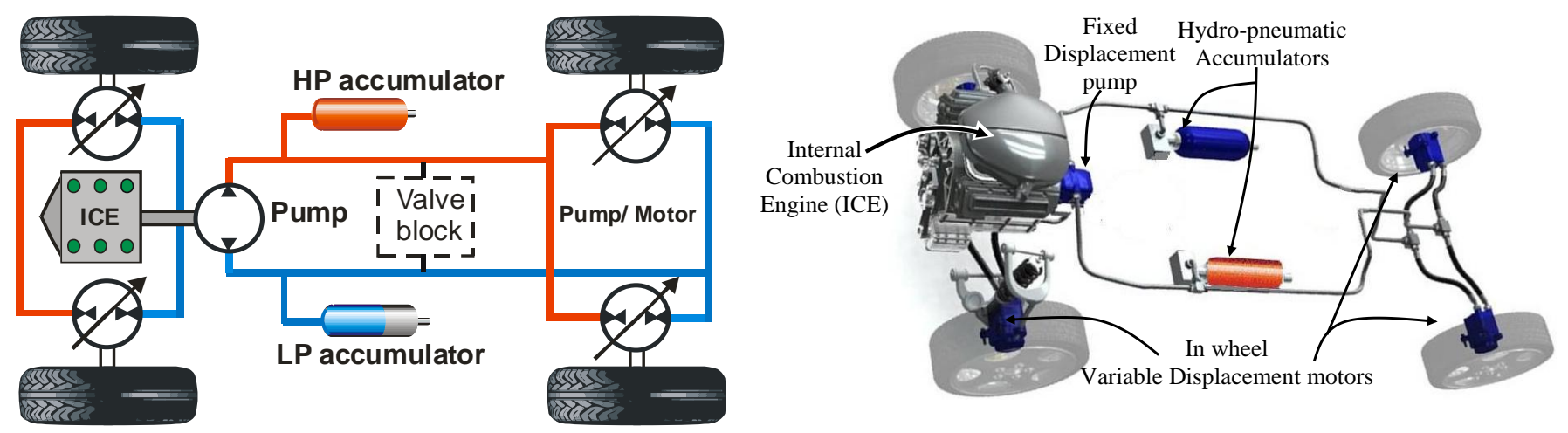

Figure (2): Layout of the SC-HST drivetrain

The complete simulation model in DSHplus environment is depicted in Figure 3. In this model the speed-controller is located at the hydro-motors to actuate their displacement according to demand at the wheels. The hydraulic circuit is equipped with a check valve at the pump output to prevent the stored energy from escaping through the pump and an electrically controlled shut-off valve block-out the flow to the motors during standstill. An additional pressure relief valve sets the maximum pressure in the circuit. The online data import (ODI) is used for implementing the NEDC cycle in the simulation while the controller tracking the required vehicle speeds.

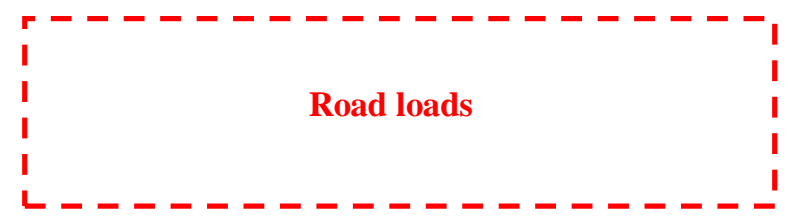




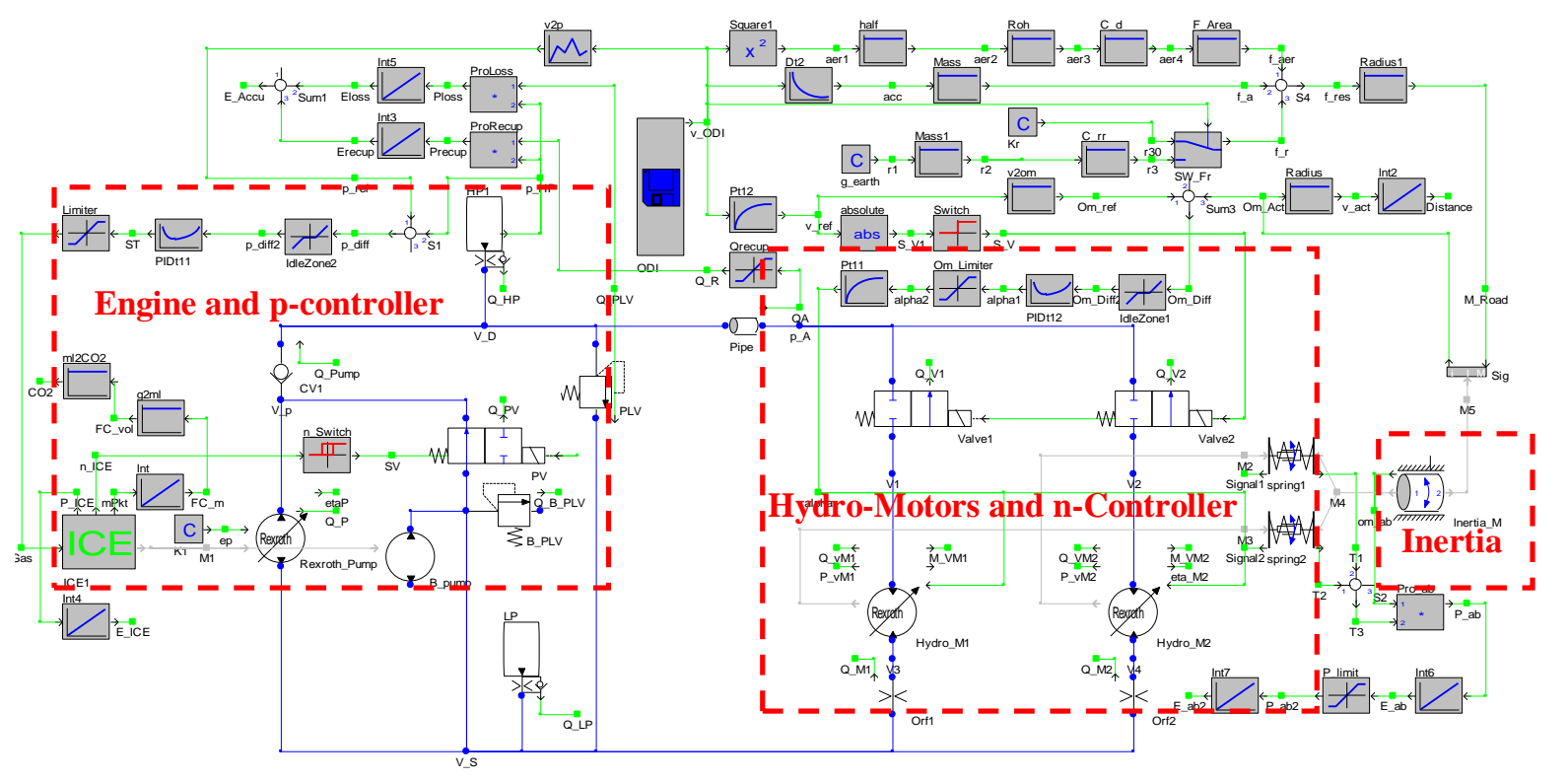

Figure (3): Simulation model of SC-HST drivetrain in DSHplus

A simplified block diagram of the SC-HST illustrating overall control strategy is indicated in Figure 4. As shown in the block diagram, the system consists of four subsystems. The first subsystem represents the engine-pump combination and its $p$-controller which controls the engine on/off according to accumulator SOC. It is responsible for converting the thermal energy into hydraulic energy to charge the accumulator. Part 2 corresponds to the storage subsystem which is a hydro-pneumatic accumulator. Part 3 represents the traction subsystem which composed of in-wheel variable displacement hydro-motors and its $n$-control to control the vehicle velocity. The interaction between these subsystems is managed by the control unit.

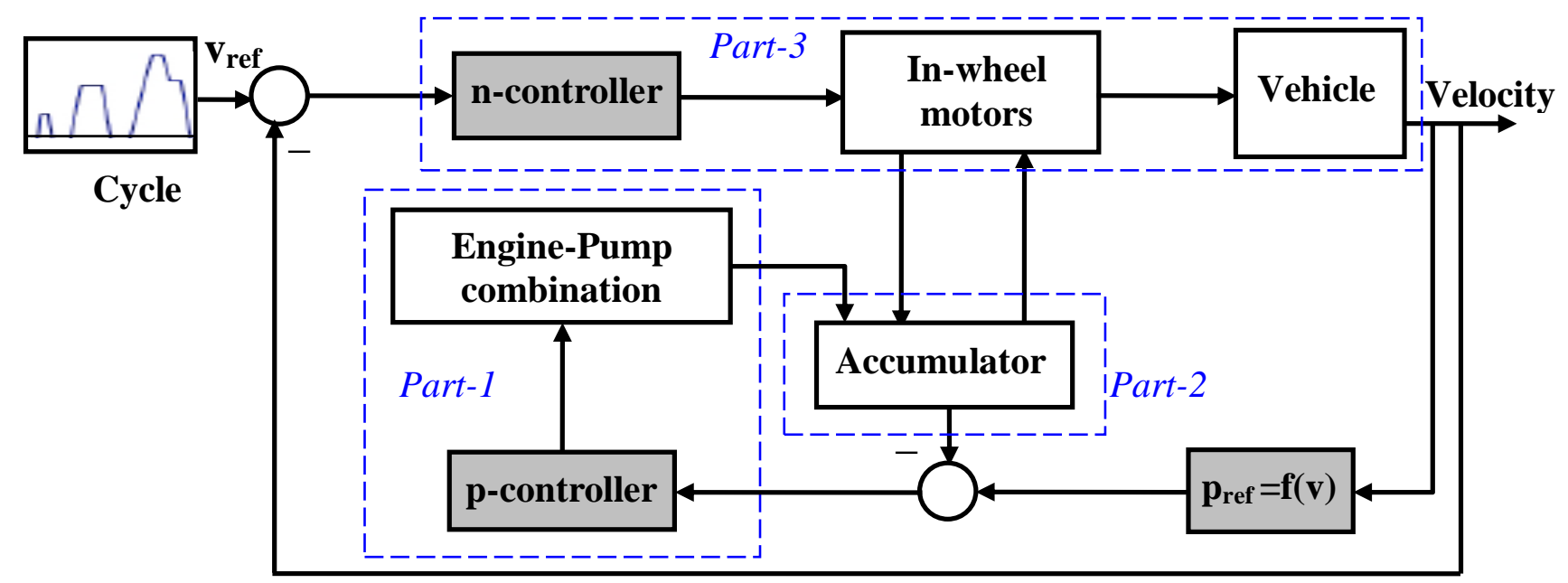

Figure (4): Block diagram indicating the overall control strategy of SC-HST

\section{2: The Hydrid drivetrain}


The hydraulic circuit of the Hydrid drivetrain has an innovative configuration proposed by Innas B.V [3] and was tested and analyzed by DSHplus simulation software tool at IFAS of RWTH Aachen University to evaluate its capabilities applying it in passenger cars [4,5]. As illustrated in Figure 5, A floating-cup type fixed displacement pump, 56 $\mathrm{cc} / \mathrm{rev}$, is coupled to the engine shaft, a high pressure accumulator is mounted on the high pressure side of the common pressure rail (CPR), and another reservoir which can be regarded as an accumulator working at low pressure (6-8 bar) is connected to the other side of the CPR. The high pressure accumulator discharges (at propulsion) or receives (at braking) its charge through the Innas hydraulic transformer (IHT) of the floating cup type with size $60 \mathrm{cc} / \mathrm{rev}$.
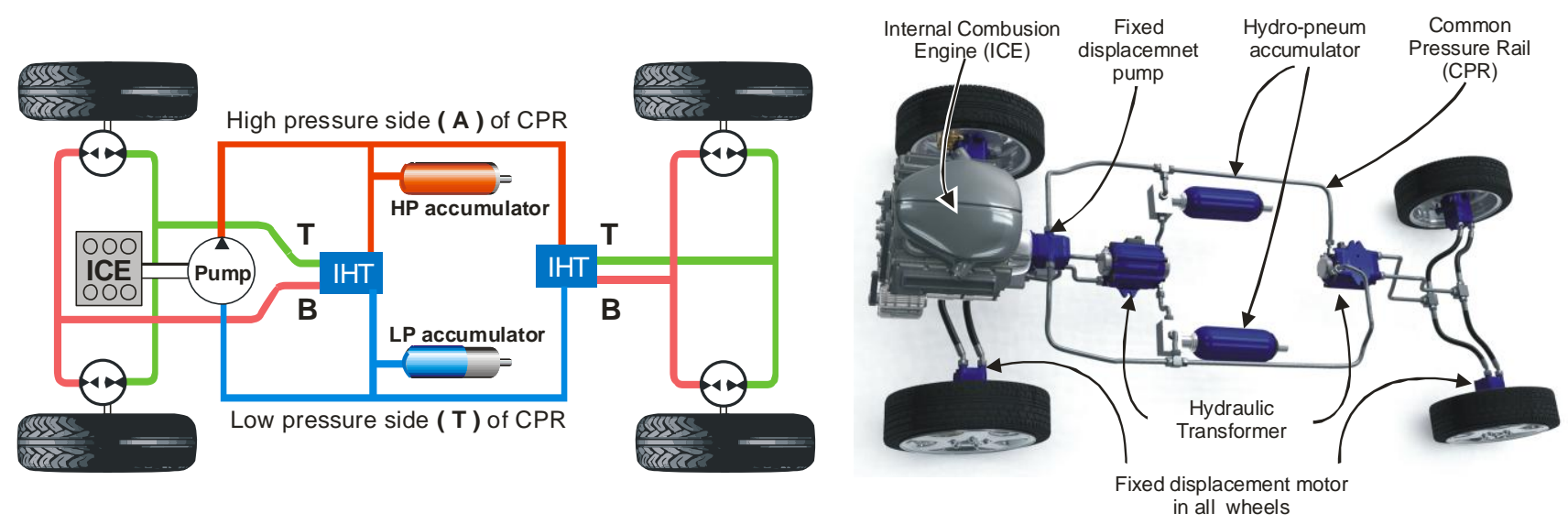

Figure (5): Layout of the series Hydrid drivetrain

The IHT is responsible for transforming power from CPR to the in-wheel hydro-motors, $60 \mathrm{cc} / \mathrm{rev}$, according to demand load in the four quadrant of operation. IHT converts the difference in pressure between the power source side and that required by the in-wheel motors on the demand side by changing simultaneously the ratio between its inlet and outlet flow. The possibility of transferring a flowrate at a relative low pressure level to another at a higher pressure level offers the option to recuperate energy from the wheel motors to the CPR and store it in the accumulator. It can transfer energy in both directions as shown in Figure 6-a, i.e. from higher to lower level on constant power basis and vice versa with high efficiency like an electric transformer.

The breakthrough technology for the Hydrid is the floating cup principle of the hydrostatic units, which aims to increase the average efficiency of all the hydrostatic components used in the Hydrid. Figure 6-b shows a unit designed to run on this principal. 

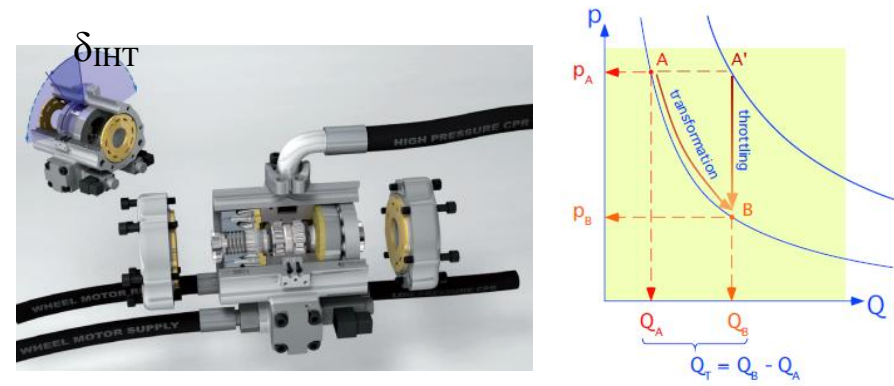

Figure (6-a): IHT operation theory [6]

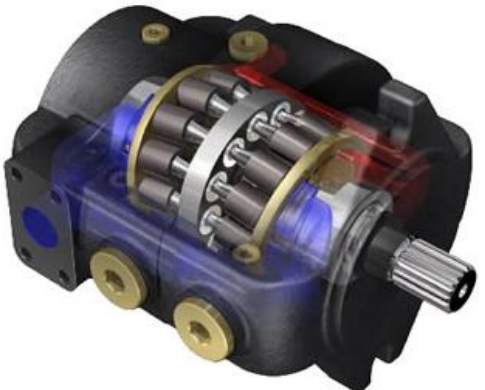

Figure (6-b): A floating cup unit [7]

Characteristics for the floating cup technology are the low friction of the pistons leading to high efficiency and low start-up torque. Noises and vibration are low due to low pulsations especially due to the high number of pistons (24 pistons) compared to the traditional units (9 pistons). The power density of the slipper type, bent axis and floating cup machine are comparable [7].

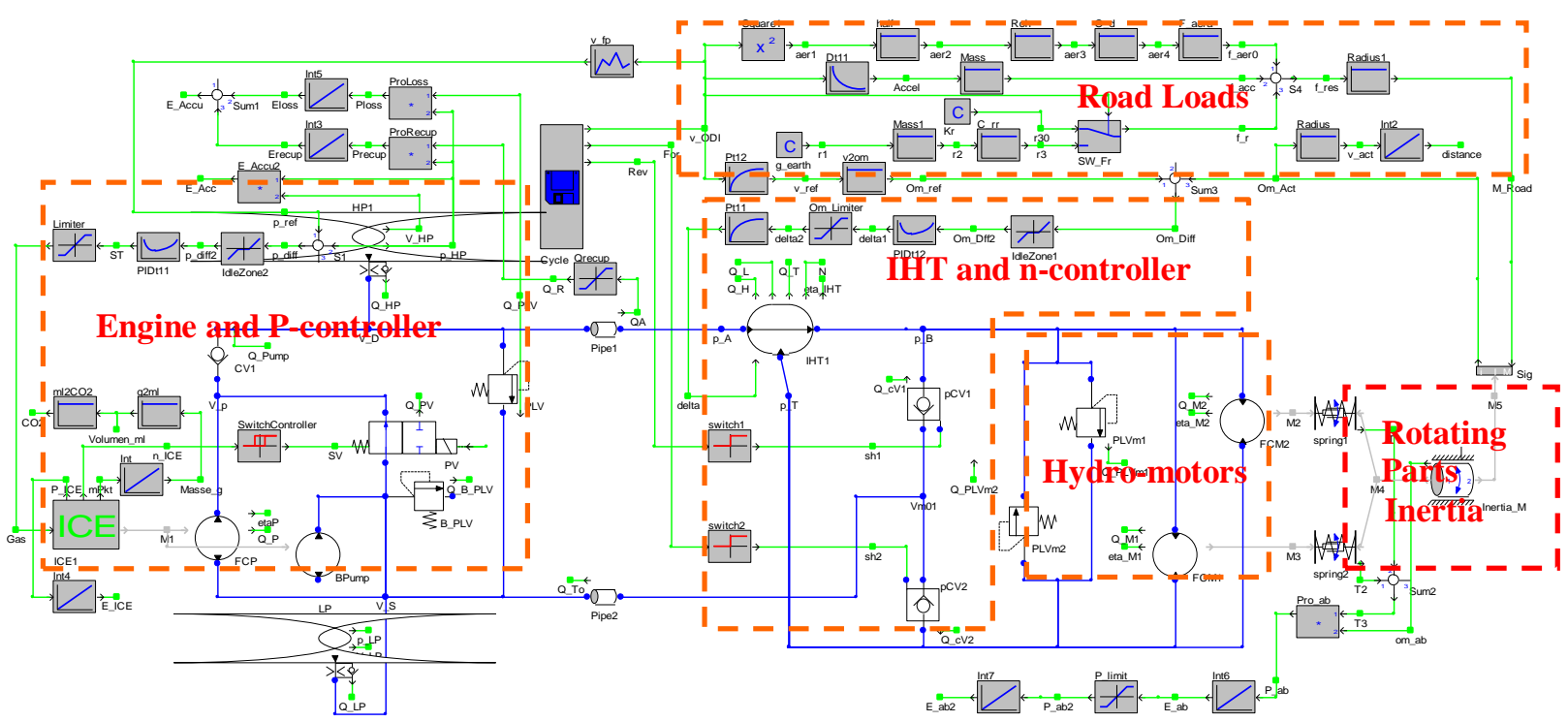

Figure (7): Simulation model of the Hydrid drivetrain in DSHplus

The system control model basically has two PID- fixed gain controllers as shown in Figure 7. One stands for controlling the high pressure line of the CPR and consequently the engine operation. The other stands for controlling the speed of the in-wheel hydromotors through the port plat angle $\left(\delta_{\mathrm{IHT}}\right)$ of the hydraulic transformer. The pressure controller comprises of a pressure transducer, amplifier, noise filter, gas throttle valve, an angular velocity switch and a solenoid venting valve (shuttle valve). The solenoid valve will also be connected to the ICE starter, so that the pump can start the engine under no-load from stand-still through stored energy in the HP accumulator. 


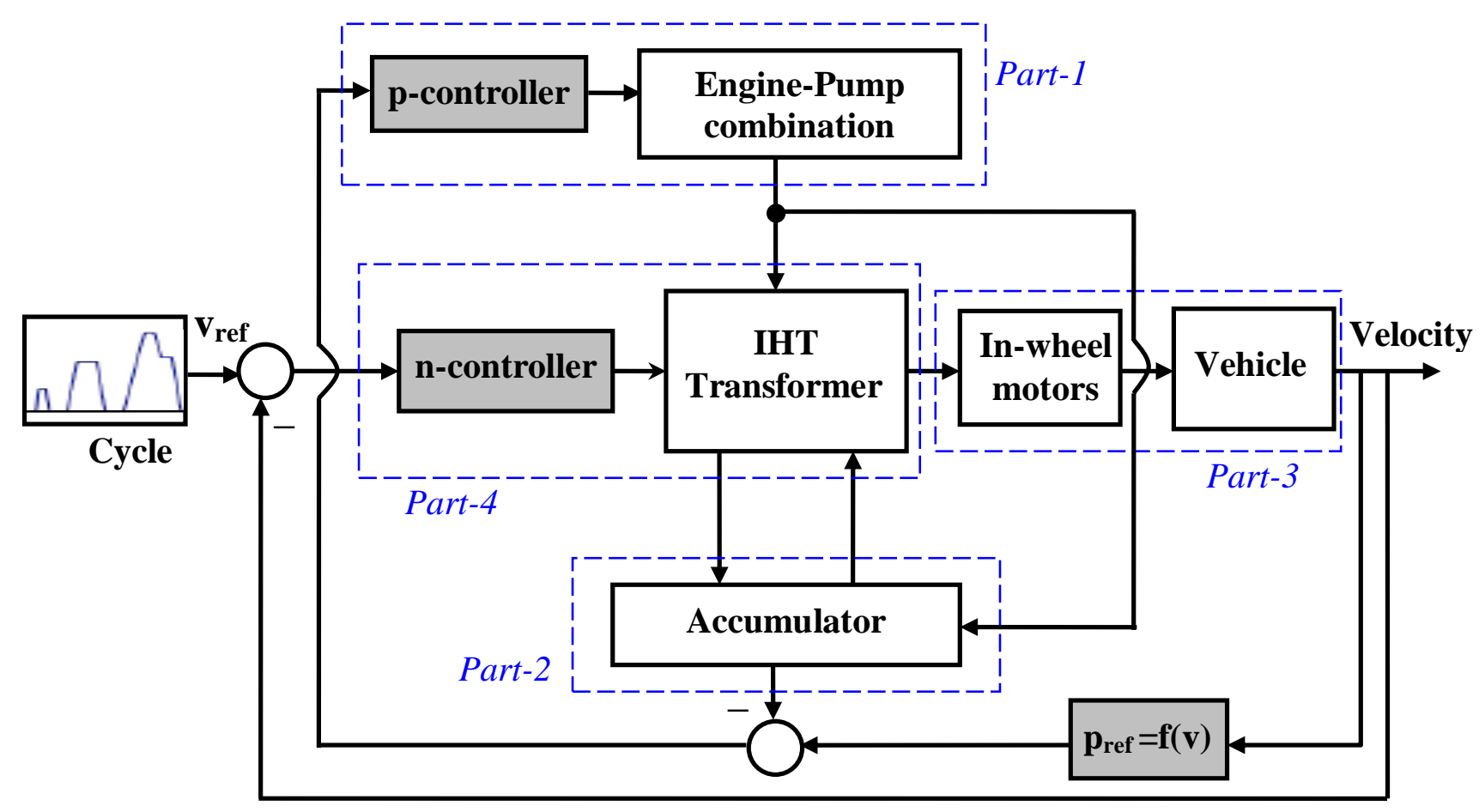

Figure (8): Block diagram indicating the overall control strategy of theHydrid

A simplified block diagram illustrating overall control strategy of the system components is indicated in Figure 8. The main difference between the Hydrid control strategy and the SC-HST is moving the speed $n$-controller from the in-wheel motors to the transformer. This is represented in the figure by part- 4 which consists of the CPR and hydraulic power transformation in addition to the $\mathrm{n}$-controller. The $\mathrm{IHT}$ is responsible to transfer the power from the accumulator to the fixed displacement motors and vice versa on constant power basis.

\section{Dynamic performance analysis}

In this section the behavior of the two introduced drivetrain concepts on dynamic performance and fuel economy will be discussed. A complete profile of the simulation results for the driving mission in NEDC cycle ( $1^{\text {st }}$ curve from below) are shown in Figures $9-a, b$. This cycle is selected for purpose of analysis as it includes hard acceleration, cruising at constant velocities and braking phases. The simulation results are performed on the on-off control strategy. All of the initial conditions and input date such as vehicle parameters and command velocity form the cycle are the same in the two models. When a low load is required by the vehicle the engine can either be shut off while the accumulator alone drives the vehicle or the accumulator increases the engine load to supply extra energy to the accumulator to be stored for later use. 

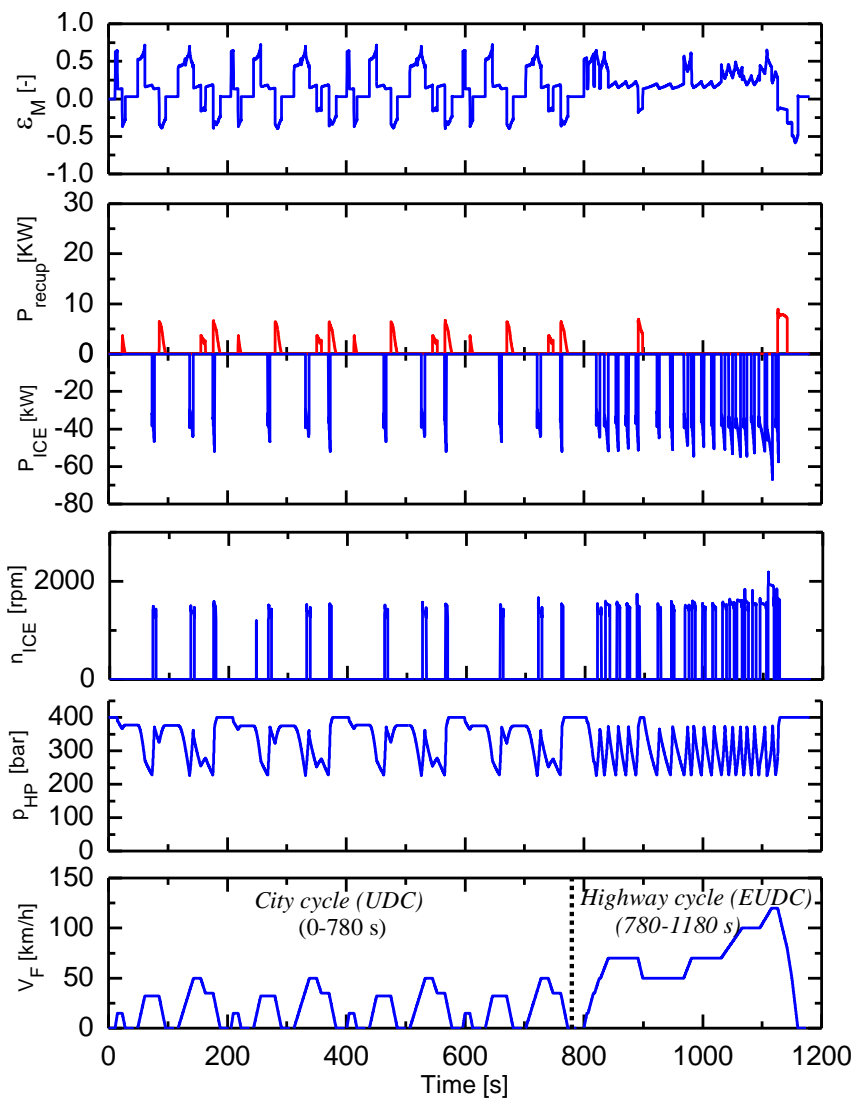

Figure (9-a): Operation of SC-HST
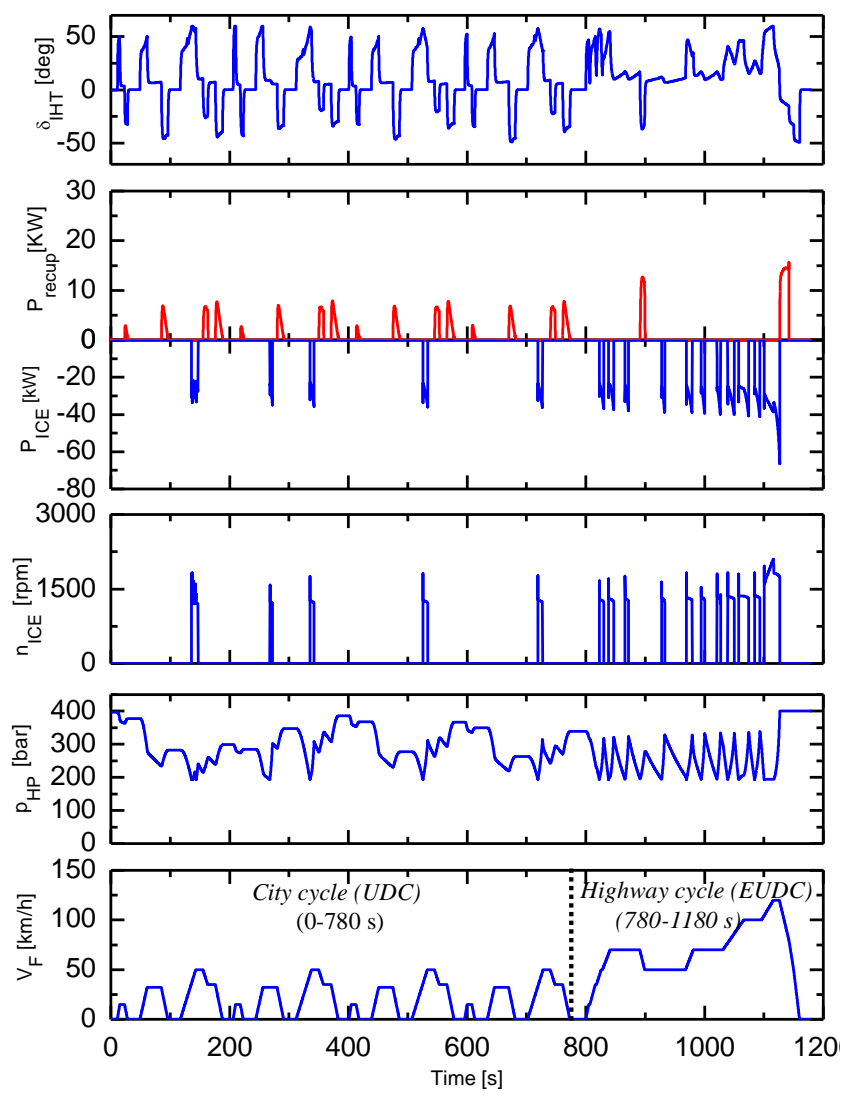

Figure (9-b): Operation of the Hydrid

Actual vehicle velocity coincides with the reference velocity along the mission NEDC cycle for both of the drivtrains as shown on the Figures $9-a, b\left(1^{\text {st }}\right.$ curve). The system analysis reveals that both of the drivetrains run approximately $16 \%$ of the mission cycle $\left(3^{\text {rd }}\right.$ curves of Figures $\left.9-a, b\right)$. But the engine in the SC-HST drivetrain runs nervously on short times as shown by the engine speed $n_{\text {ICE }}\left(3^{\text {rd }}\right.$ curve of Figure 9-a), otherwise the same control methodology as in the Hydrid was applied. This is due to the pressure difference on the accumulator is the same that on the wheel motor, i.e. the pressure on load side is the same on the source side, causing high variations in the working pressure during the cycle. On the other side in the Hydrid the hydraulic transformer covers the gap in pressure differences between load and source sides allowing smooth and steady operation for the engine. The system pressure in both drivetrains is maintained in the secure range of 200-400 bar ( $2^{\text {nd }}$ curve). The angular position of the IHT port-plate $\delta_{\mathrm{HT}}$ and the displacement of the variable displacement hydro motor in the SC-HST have a positive angles in propulsion mode and negative angles during braking mode $\left(6^{\text {th }}\right.$ curve). The amount of recuperated power of the Hydrid $\left(5^{\text {th }}\right.$ curve of Figures $9-\mathrm{a}, \mathrm{b})$ during braking is greater than of the SC-HST by $18 \%$. While the engine consumes higher power in the SC-HST compared to the Hydrid to do the same task ( $4^{\text {th }}$ curve).

The engine will run in the Hydrid after $136 \mathrm{sec}$ from cycle start rather than $75.5 \mathrm{sec}$ in the other (refer to $3^{\text {rd }}$ curve of Figure 9-a, b), because in the Hydrid the transformer covers the gap in pressure by providing the hydro- motors with the required pressure. 

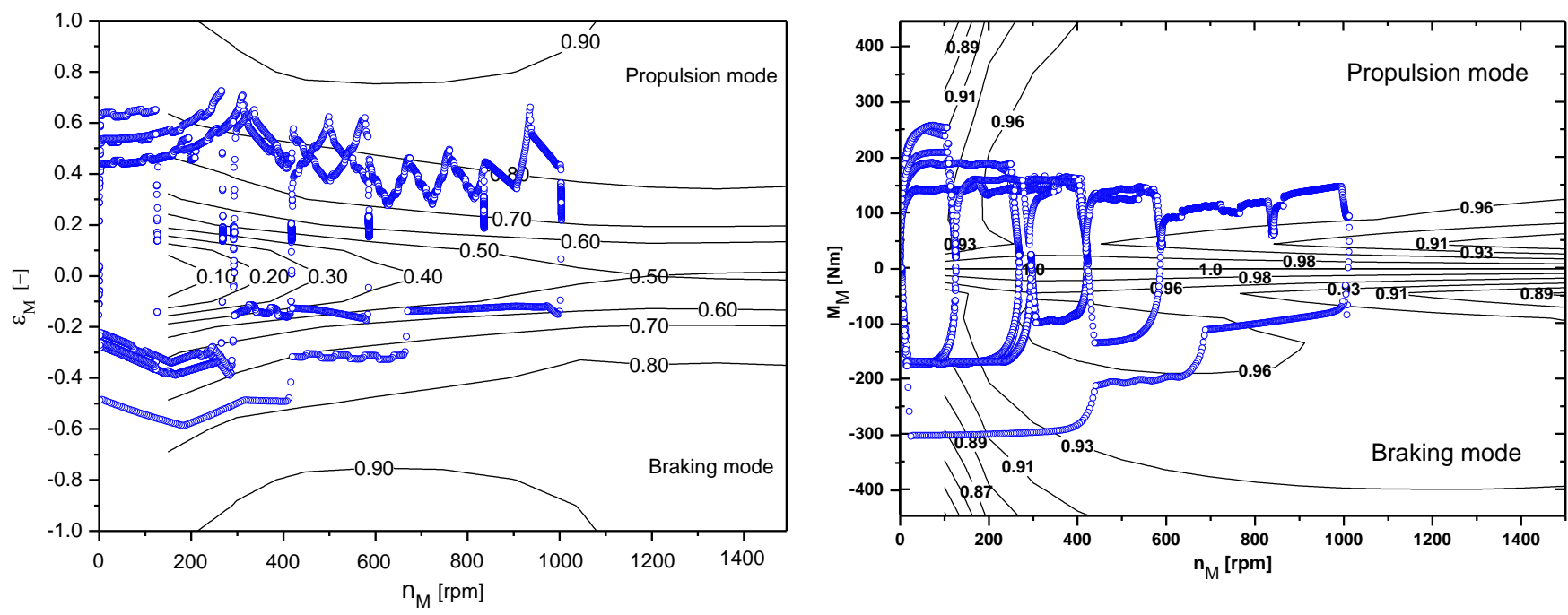

Figure (10): SC-HST's motors operating point Figure(11): Hydrid's motors operating point

The operating points of the hydro-motors which are depicted in Figure 10, 11, shows that the constant displacement floating cup motor as used in the Hydrid will operate at higher average efficiency approximately $96 \%$ during propulsion mode and average of $94 \%$ during braking mode compared to $80 \%$ at propulsion and $65 \%$ at braking in the traditional variable displacement motors used the SC-HST. Moreover the transformer permits small size motors because it can amplify the pressure level on the motor side to 500 bar, even when the pressure level in the accumulator is only 200 bar. But in SCHST the motor displacement needs to increase to substitute the lower pressure to create the same maximum torque. The worst case occurs when the pressure reaches the minimum limit, requiring an adequate motor size.

\section{Fuel consumption and $\mathrm{CO}_{2}$ emissions}

Fuel consumption and $\mathrm{CO}_{2}$-emission resulting from the simulation models of the SCHST and the Hydrid are compared to the baseline vehicle as shown in figures 12 and 13. The results show that the fuel consumption and consequently $\mathrm{CO}_{2}$-emissions are reduced by amount of 30\% in the SC-HST and more than 50\% in the Hydrid compared to the conventional vehicle. The $\mathrm{CO}_{2}$-emissions is reduced to $82 \mathrm{~g} / \mathrm{km}$, far below the limits set by the European Commission of $130 \mathrm{~g} / \mathrm{km}$ at year 2012, and even below the long term target of $95 \mathrm{~g} / \mathrm{km}$ as a limit for 2020 . 


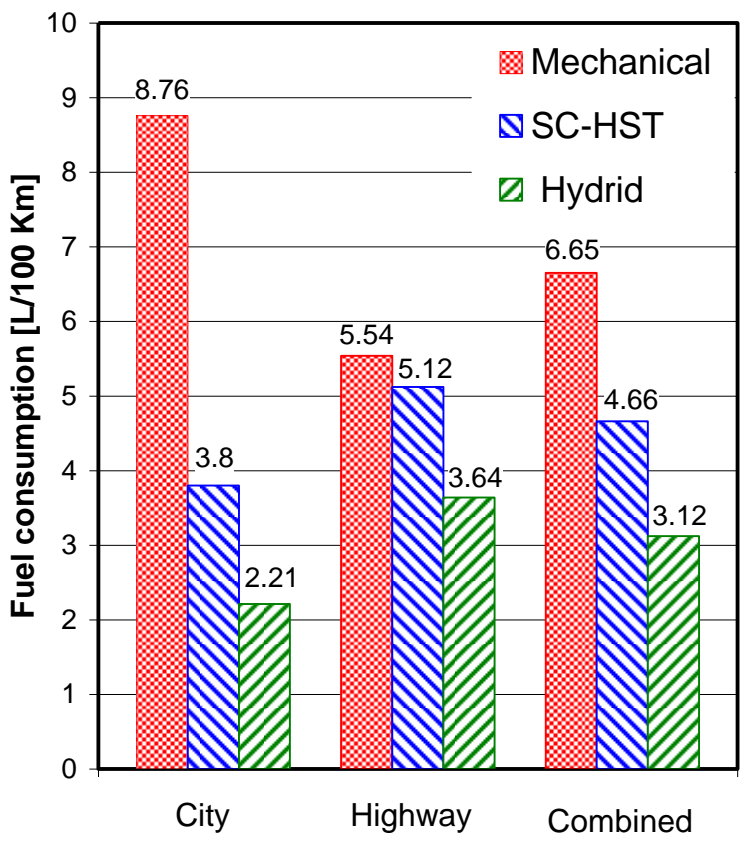

Figure (12): Fuel consumption over the NEDC

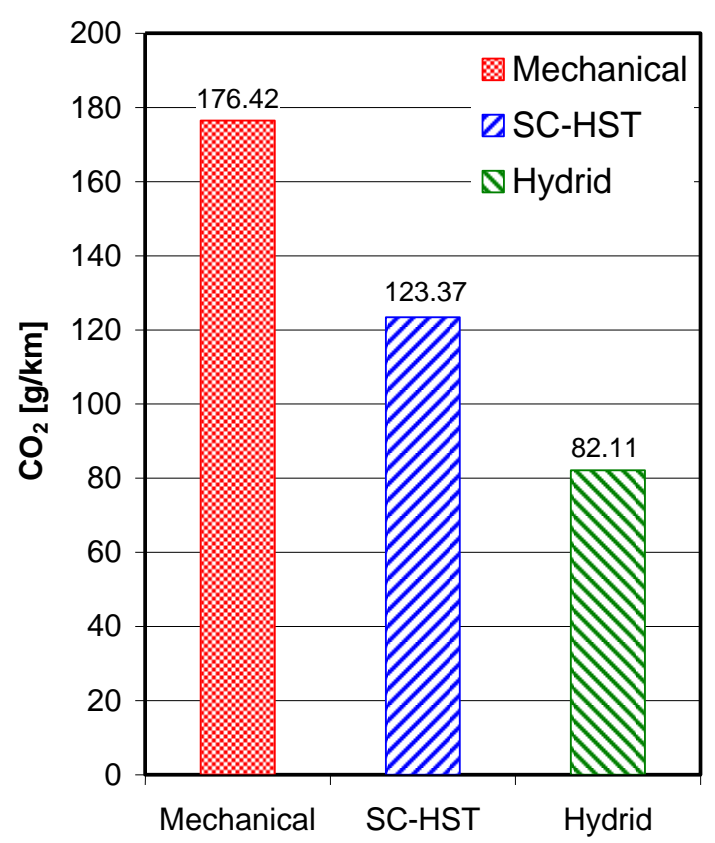

Figure (13): $\mathrm{CO}_{2}$ emission over $N E D C$

\section{Conclusions:}

This paper assesses the potential fuel savings and emissions reductions associated with hydraulic hybridization for mid-sized passenger cars such as VW Sedan Passat vehicle. As a main factor of consuming high fuel in mechanical transmission vehicles is operation the engine at low and partial loads, where at these points engine efficiency is very low. The results indicate that the series hydraulic hybrid has the potential to reduce fuel consumption and consequently $\mathrm{CO}_{2}$ as the engine is forced to run only under high loads due to the controlled effective range of accumulator pressure (200-400 bar). SCHST offer good fuel saving approx. 30\%, but it still suffers from high pressure variation, low efficiency especially at low motors displacements. Furthermore, variable displacement motors require large sizes to cover traction needs at the wheels because its working pressure is limited to 400 bar. Using the particular Hydrid drivetrain configuration, where pressure at the accumulator side is separated from load side at the hydro-motors by the IHT. The IHT mange system pressure according to load demands and covering the gap between source side and load side. It can amplify the pressure level on the motor side to $500 \mathrm{bar}$, even when the pressure level in the accumulator is only 200 bar which permit a small motors size. The results reveal that the Hydrid is a promising concept and can be used effectively in passenger cars. It can compete with the electric hybrid vehicles due to their high efficiency components, robust control and high power density. Based on today's technology, the potential fuel economy gains average about $53 \%$ for mid-sized cars by using the new component, such as the floating cup units and the IHT, connected in distinct configuration as in the Hydrid.

\section{References:}


[1] Palmen, A. et al, Wirkungsgraduntersuchung an einer Floating CupAxialkolbenpumpe. IFAS of RWTH Aachen, 2007

[2] K.E. Rydberg, Energy efficient Hydraulic Hybrid Drives, Proc. of the $11^{\text {th }}$ Scandinavian International Conference on Fluid Power, June 2-4, 2009

[3] P. Achten, The Hydrid transmission, Proc. SAE 2007 Commercial Vehicle Engineering Congress \& Exhibition, October 2007, USA, SAE 2007-01-4152.

[4] P. Achten, G. Vael, T. Kohmäscher, M. Ibrahim-Sokar, Energy efficiency of the Hydrid, Proc. Int. Fluid Power Conference 6. IFK, Dresden, Germany, 2008.

[5] P. Achten, G. Vael, T. Kohmäscher, M. Ibrahim-Sokar, Design and fuel economy of a series hydraulic hybrid vehicle, Proceedings of the 7th JFPS International Symposium on Fluid Power, TOYAMA, 2008

[6] Vael, G.E.M et al, The Innas Hydraulic Transformer - The Key to the Hydrostatic Common Pressure Rail, SAE 2000-01-2561.

[7] Platzer, T., van Malsen, R. and Achten, P., Floating Cup - Ein neues Konstruktionsprinzip für hydrostatische Maschinen", O+P, Nr. 6, 2004

\section{Nomenclatures:}

$\delta_{\mathrm{HHT}} \quad$ Innas Hydraulic Transformer's angle [deg]

$\varepsilon_{\mathrm{M}} \quad$ Setting displacement ratio of hydro-motors [-]

$\mathrm{M}_{\mathrm{M}} \quad$ Hydro-motor torque [Nm]

$v_{\text {IXE }} \quad$ Internal Combustion Engine speed [rpm]

$\mathrm{n}_{\mathrm{M}} \quad$ Hydro-motor speed [rpm]

$V_{F} \quad$ Vehicle velocity $[\mathrm{km} / \mathrm{h}]$

$\mathrm{P}_{\mathrm{ICE}} \quad$ Internal Combustion Engine power $[\mathrm{kW}]$

$P_{\text {recup }}$ Recuperated power $[\mathrm{kW}]$ 